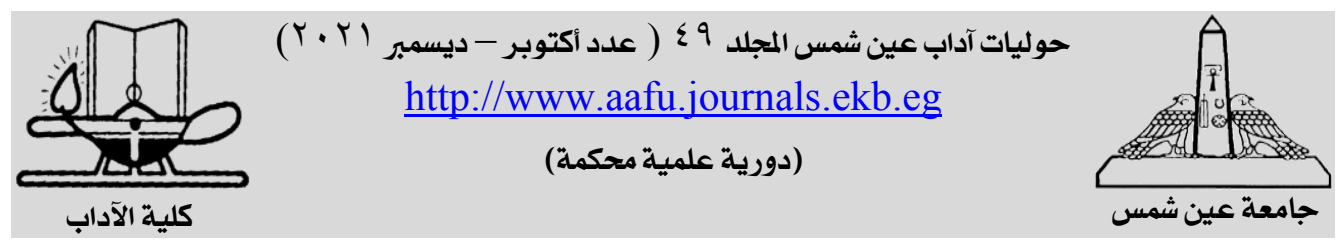

تأويل الموصولات الاسمية في متشابه القرآن اللفظي

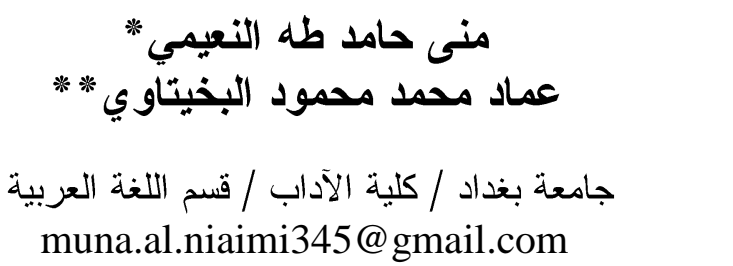

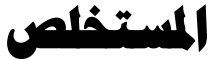

تعدّ الموصولات الاسمية من المعارف التي نالت نصيبها من التأويل في كتب

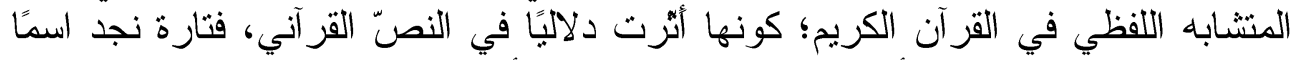

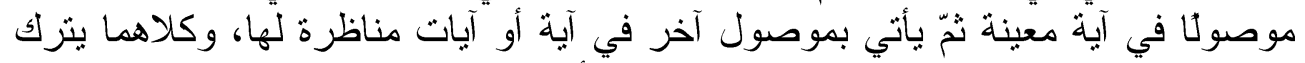
بصمات دلالية لا نجدها لو لا هذا التغاير. وقد أثنارت هذه الموصولات التات الاسمية اهتمام

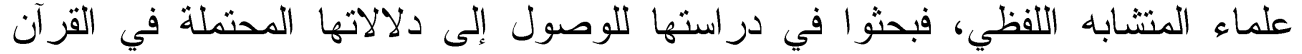

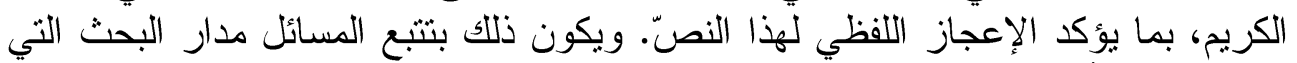

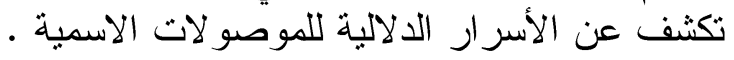




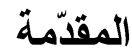

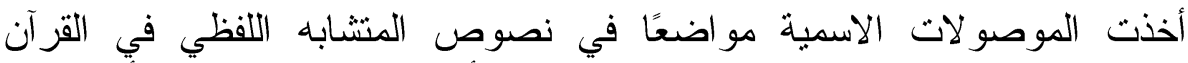

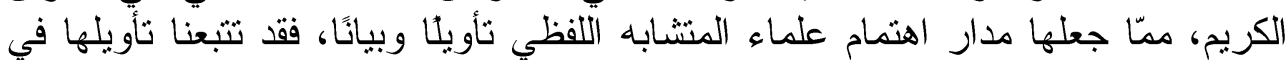

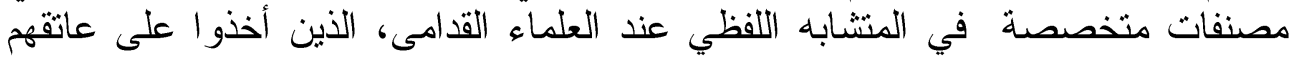

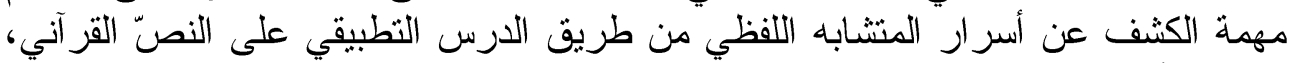

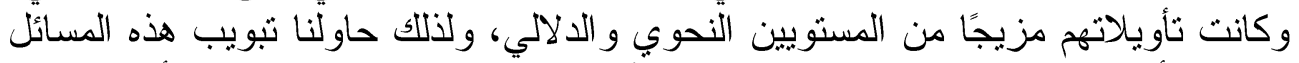

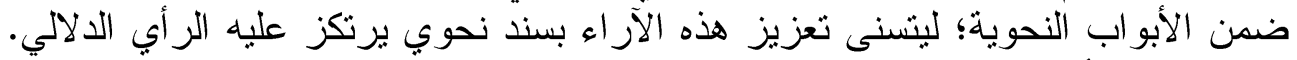

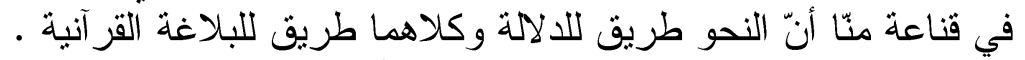

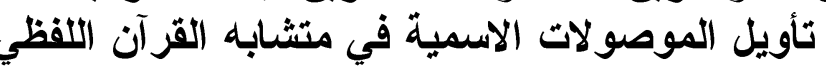

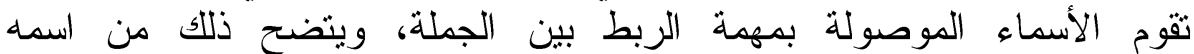

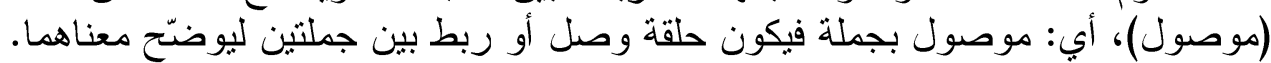

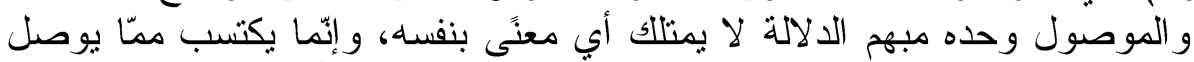

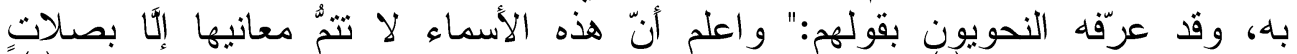

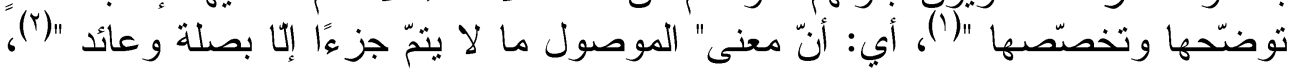

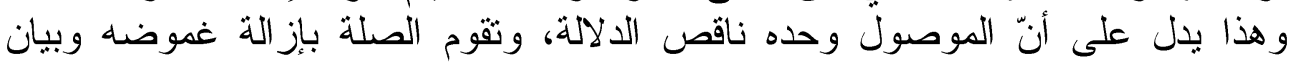

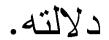

و عرض النحويون لدراسة الصلة منذ بداية الدرس النحوي؛ لأنها لم تكن منفصلة

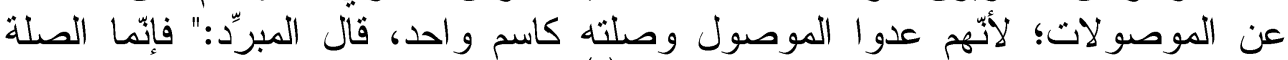

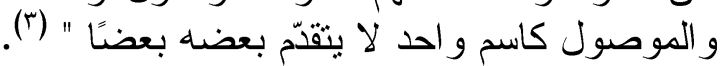

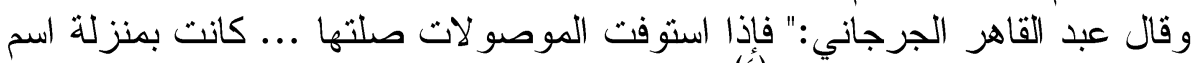

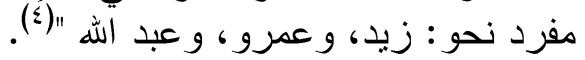
ويرى الدكتور مهدي المخزومي أنّ الاسم الموصول يؤنتى به في التركيب الجملي

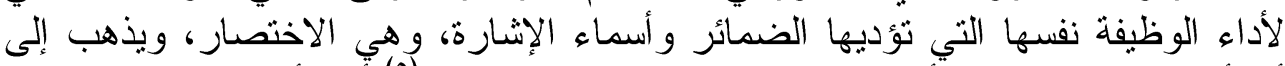

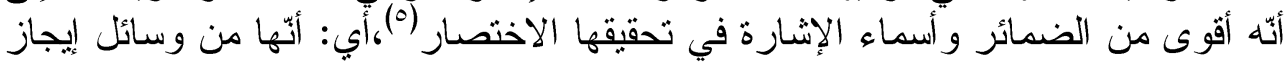

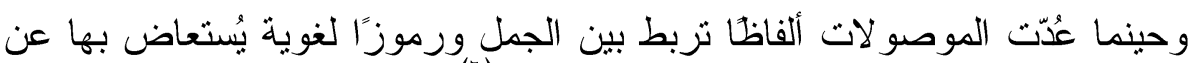

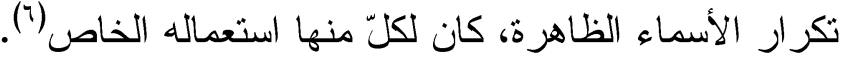

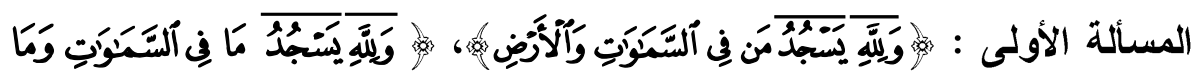

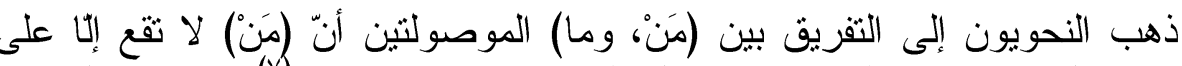

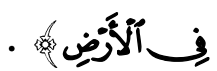

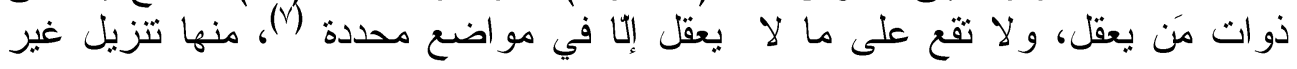

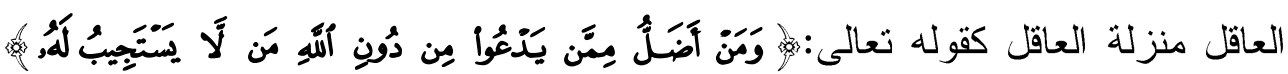

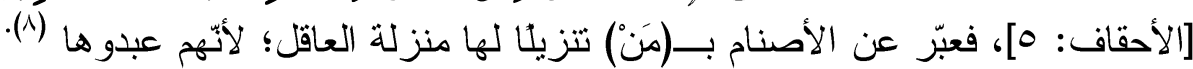


أمّا (ما) فتقع على ذوات ما لا يعقل وصفات مَن بعقل، فمين الأول قوله تعالى :

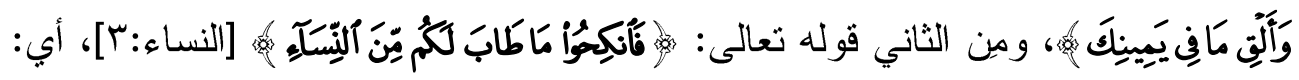

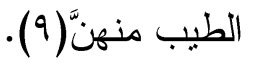

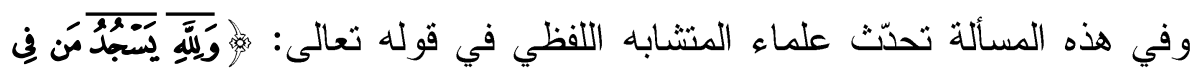

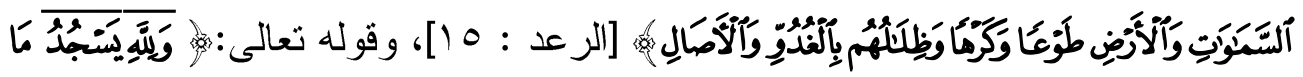

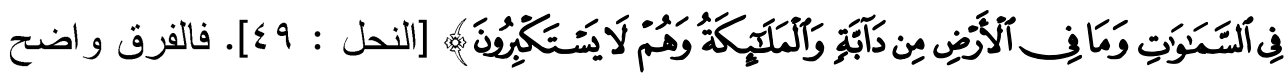

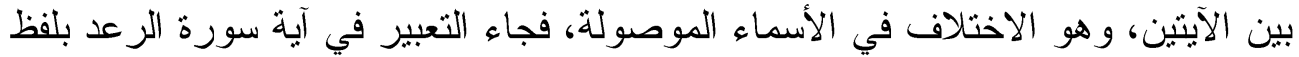

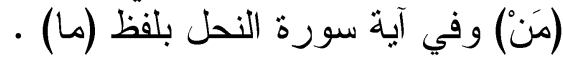

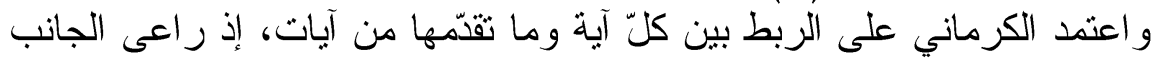

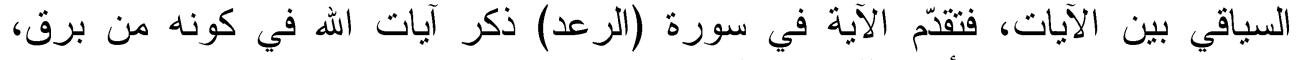

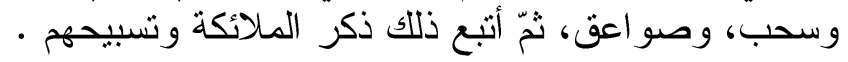

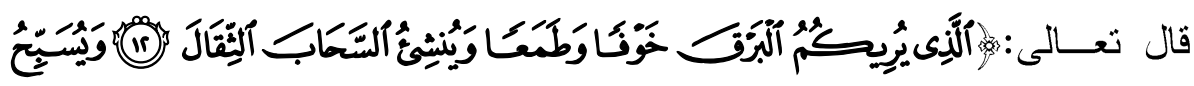

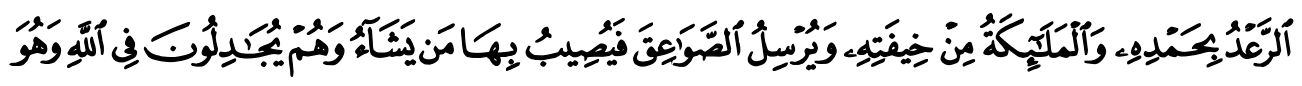

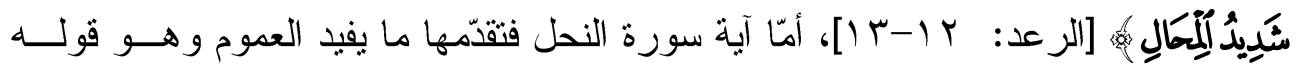

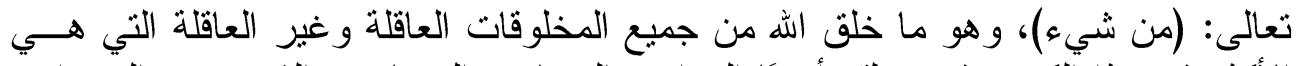

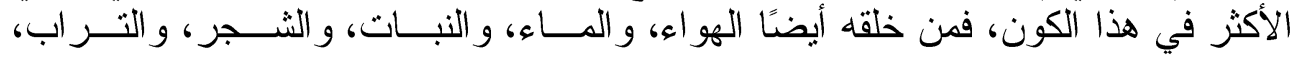

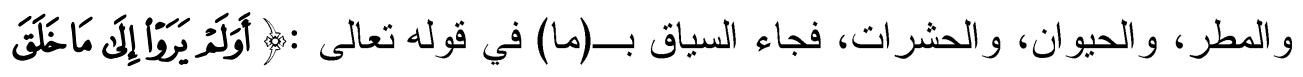

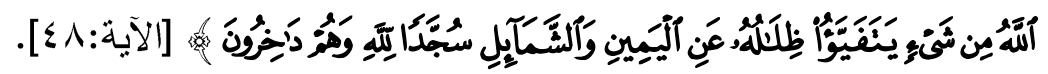

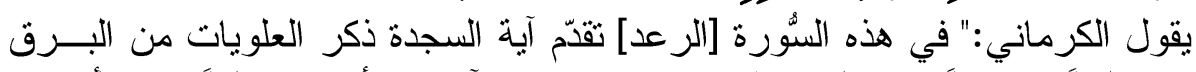

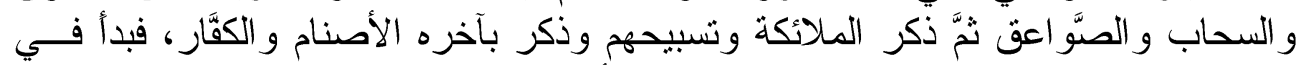

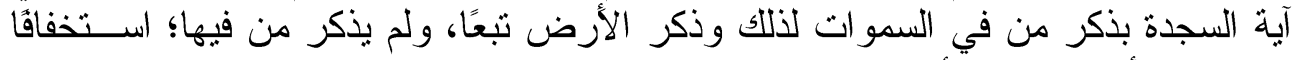

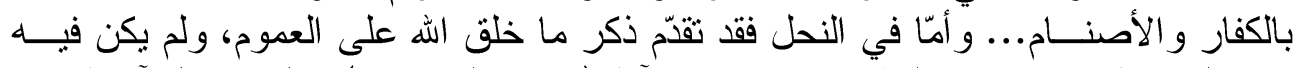

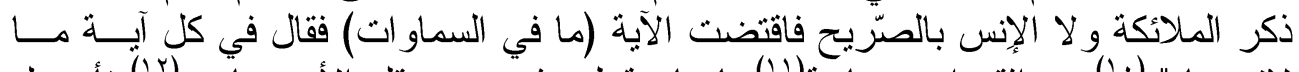

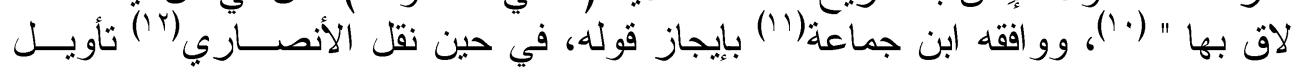

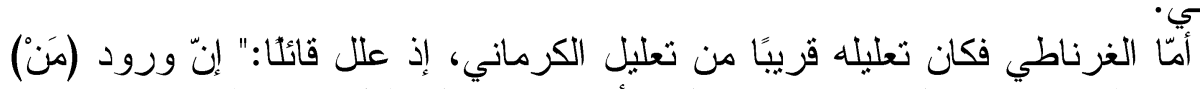

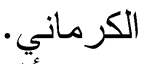

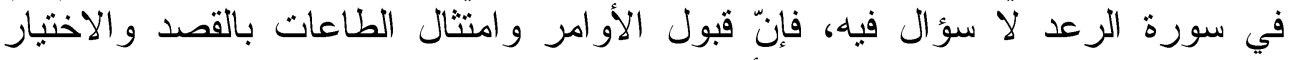

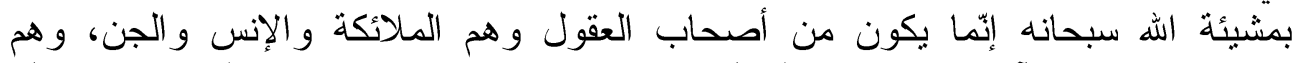

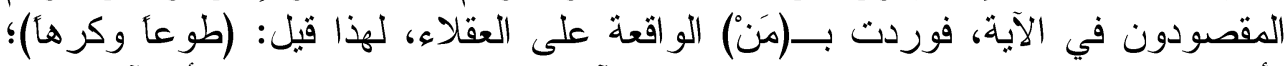

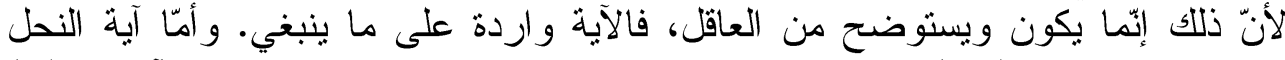

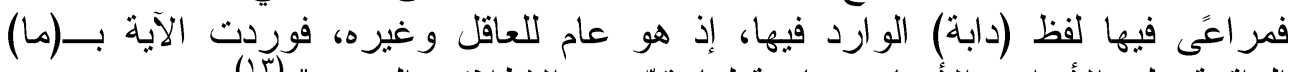

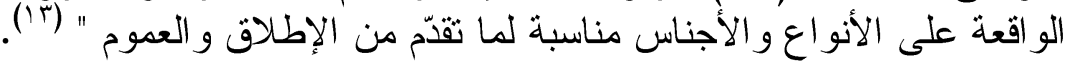


و على ذللك فاستعمال (مَنْ) كان لغاية بلاغية هي تنزيل غير العاقل منزلة العاقل

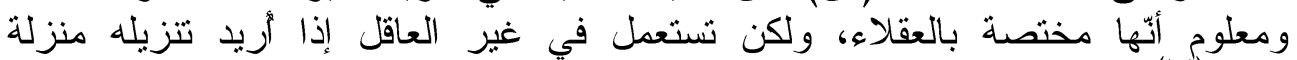

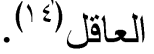
وممّا يؤكد أنّ (مَنْ) نأتي شاملة للعاقل وغير العاقل الذي هو بمنزلة العاقل قوله

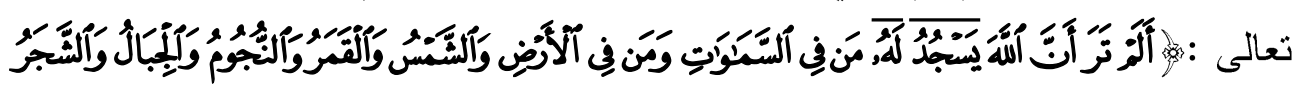

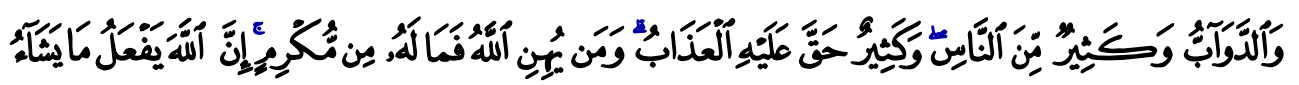

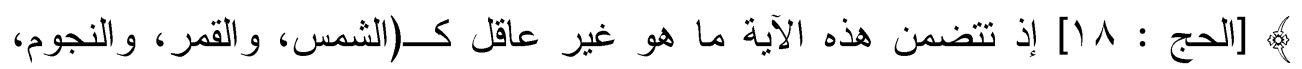

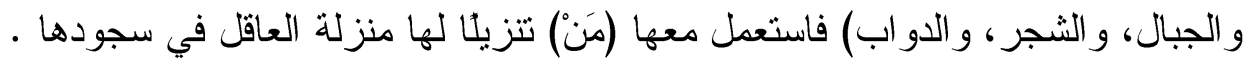

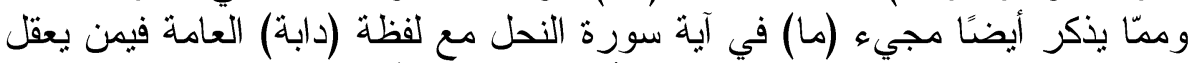

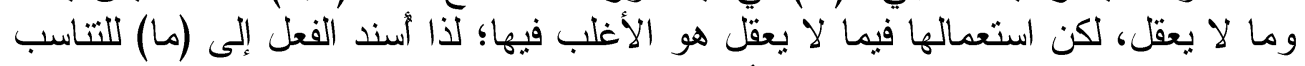

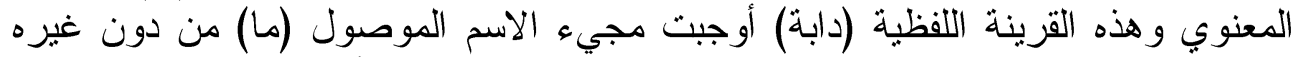

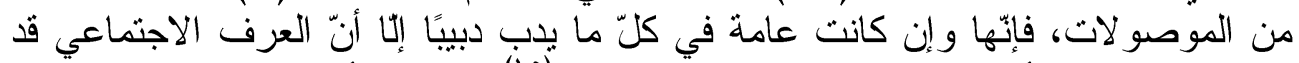

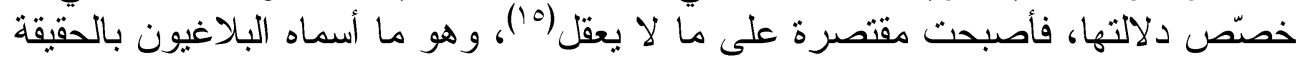

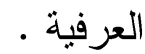

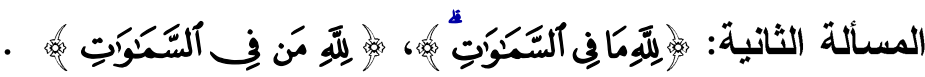

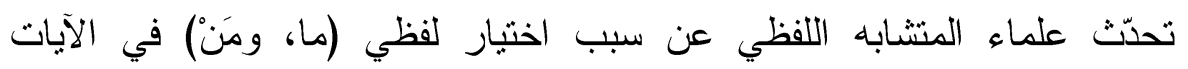

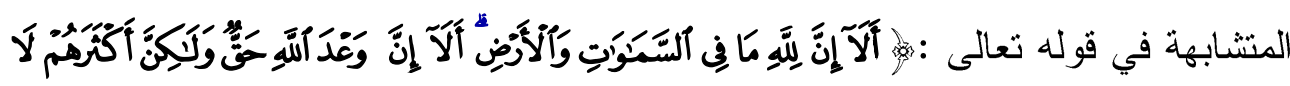

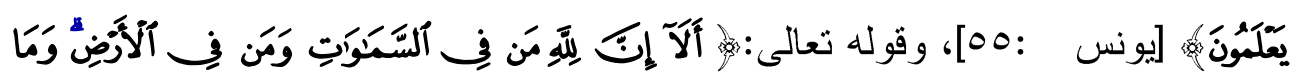

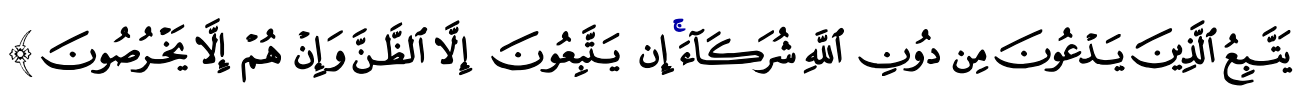
[يونس :

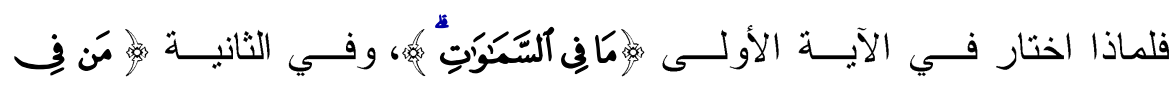

يجيب الخطيب الإسكافي أن " اختصاص (ما) حيث اختصت، واختصاص (مَنْ)

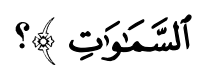

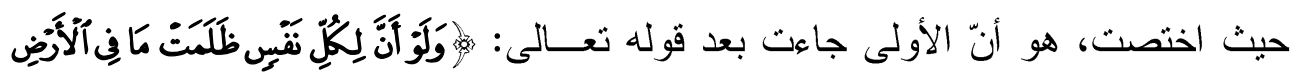

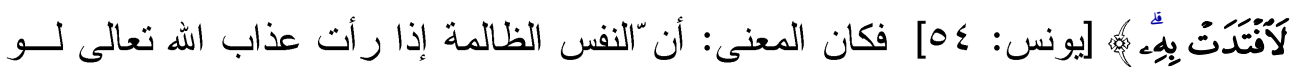

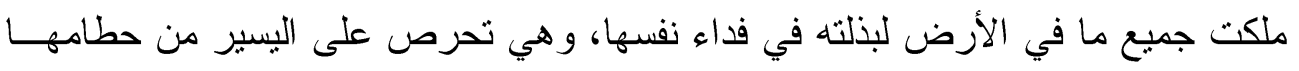

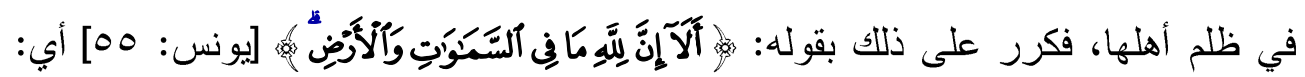

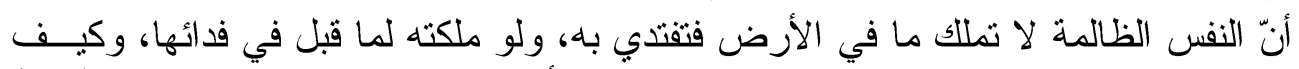

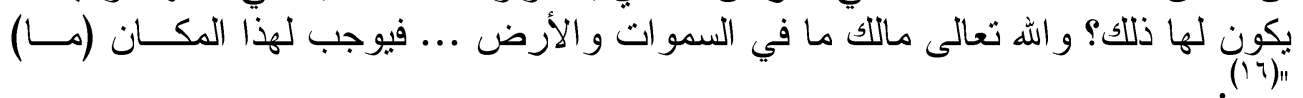


في حين رأى عدم صحّة ذكر غير (مَنْ) في الموضع الذي ذكرت فيه " لأنّ قبله

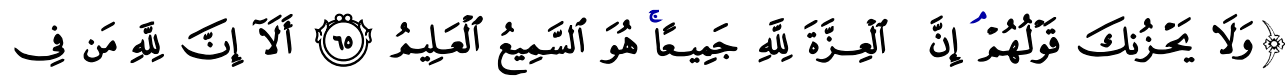

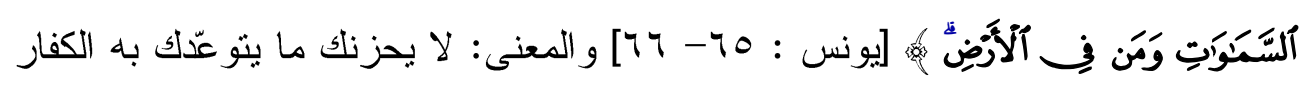

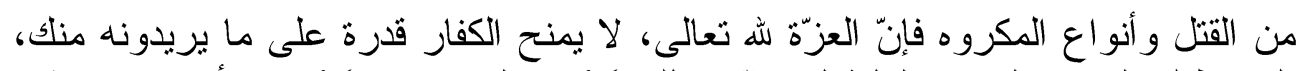

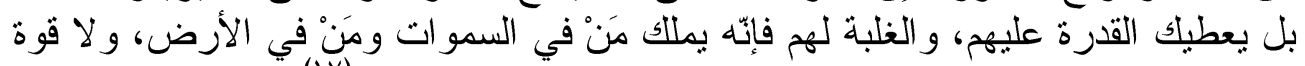

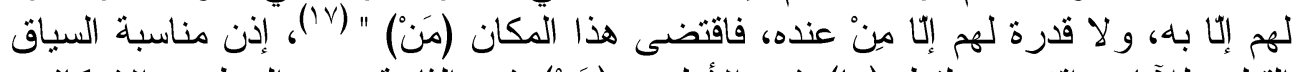

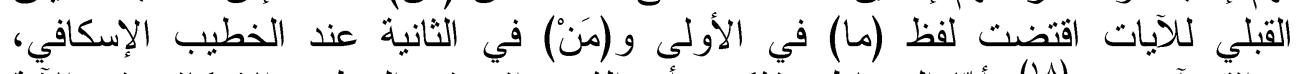

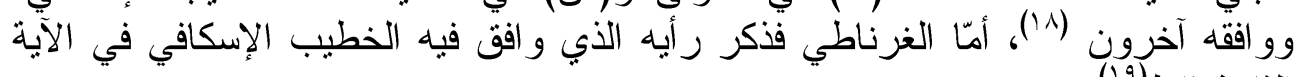

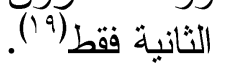

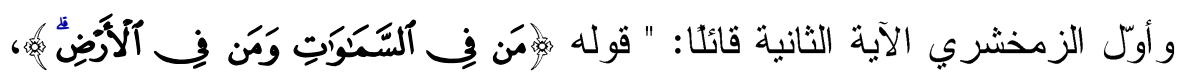

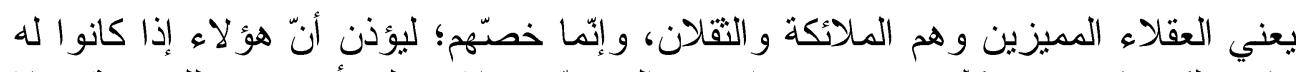

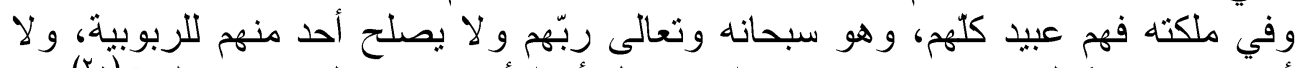

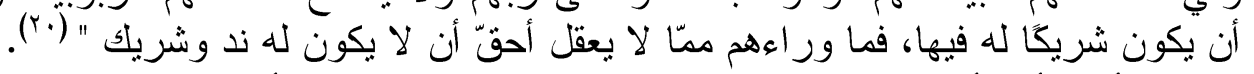

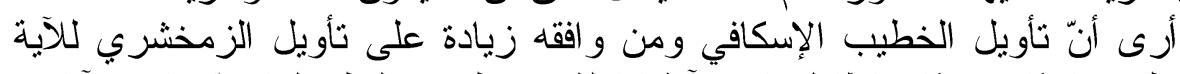

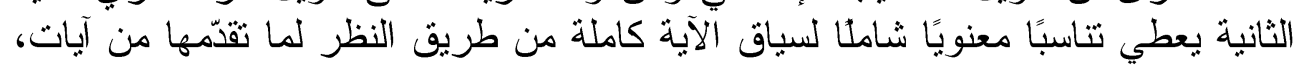

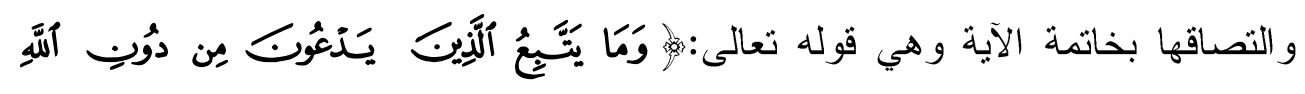

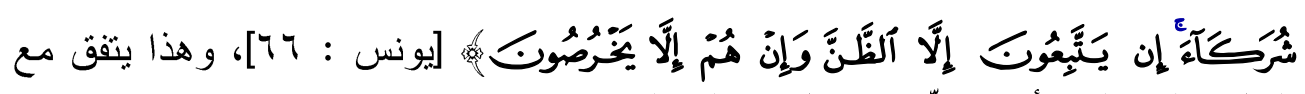

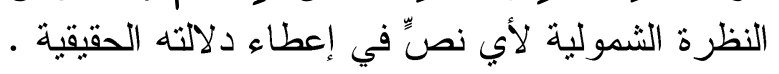

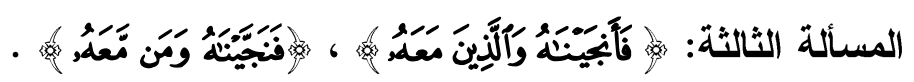

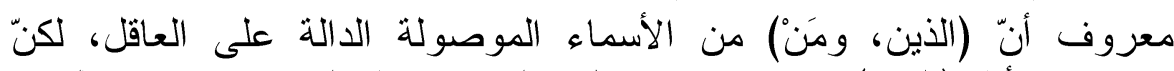

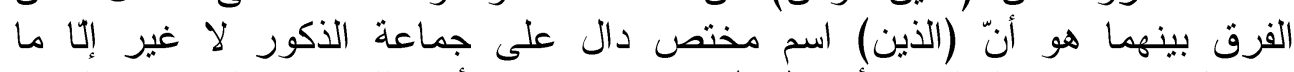

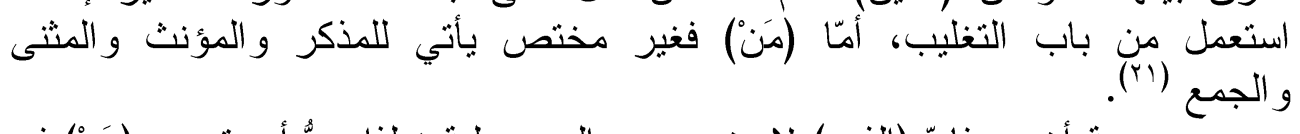
من جهة أخرى فإنّ (الذين) لا يخرج عن الموصولية ؛ لذا يعدُ أعرق من (مَنْ) في

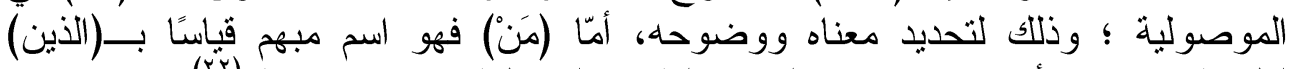

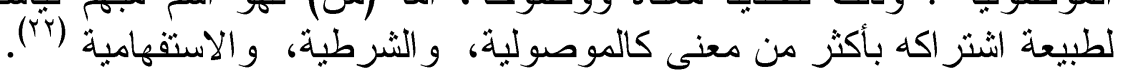

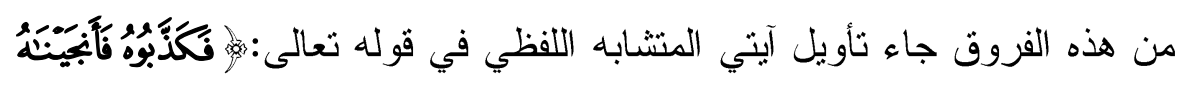

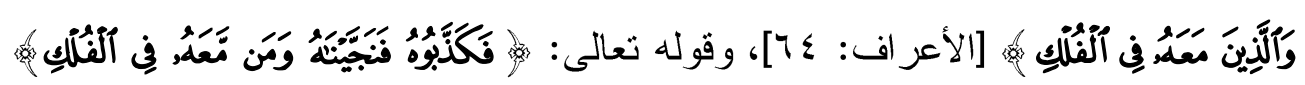

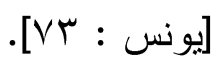
مع اتفاق التعبيرين في القصد إنا أنّها اختلفا في الموصول الأسمي، إذ جاء إناء

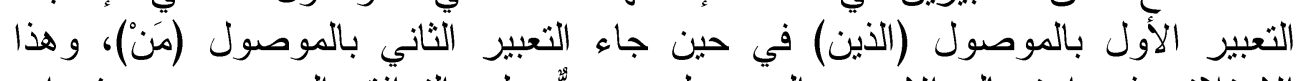

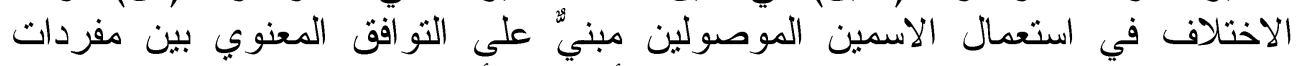

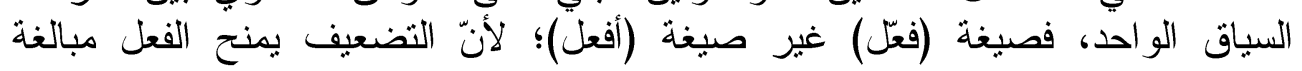
وكثرة. 


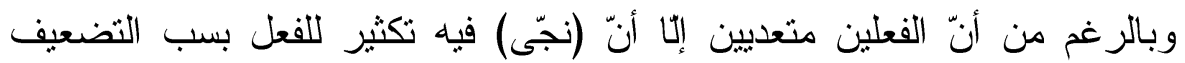

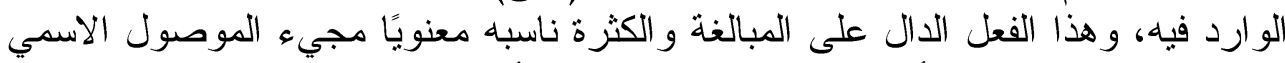

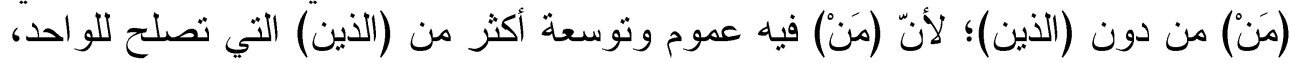

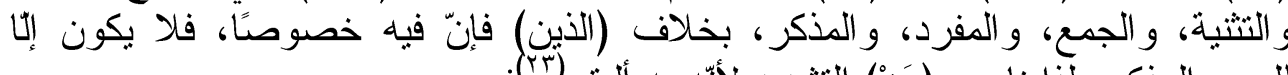

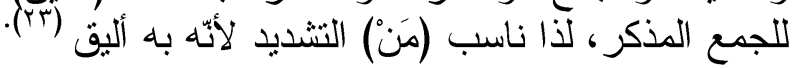

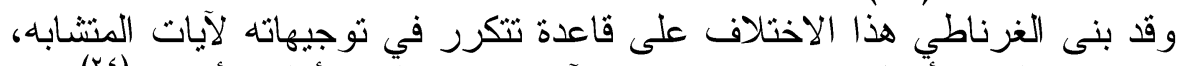

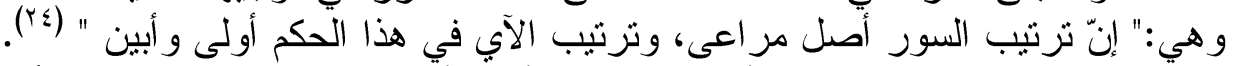

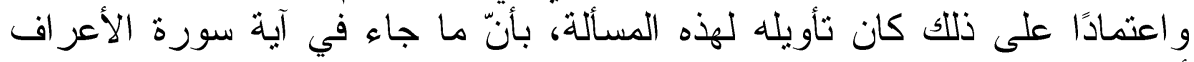

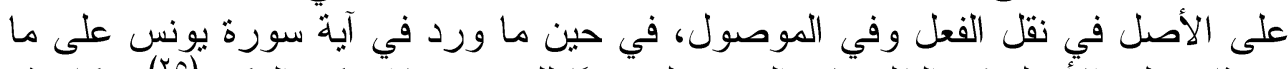

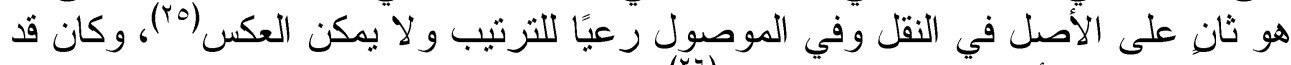

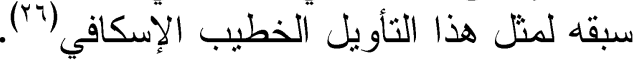

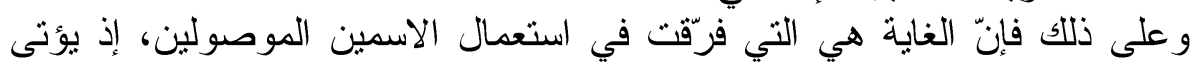

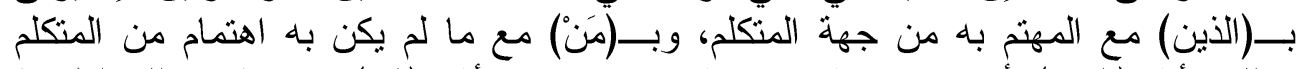

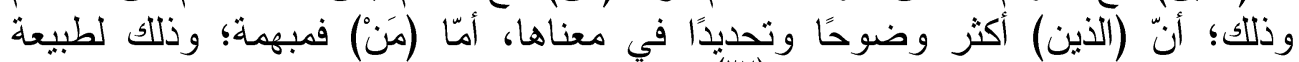

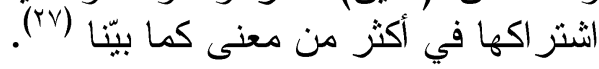

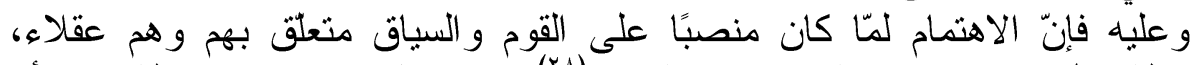

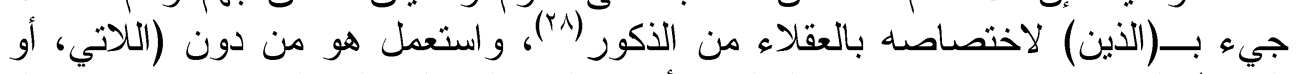

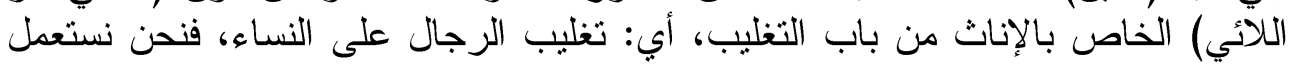

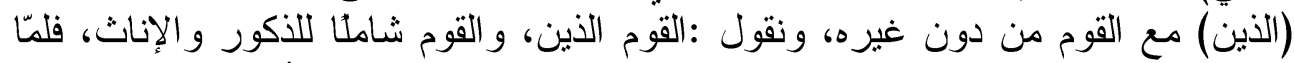

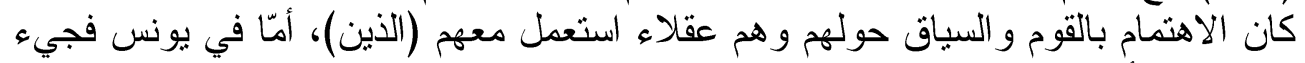

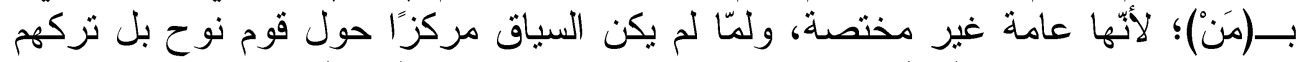

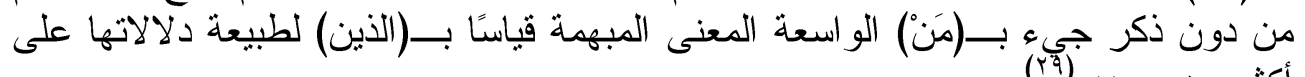
وربّما كان تعدد أغر اض الاسم الموصول كالإبهام، و التحقير ، و التعظيه، و إرادة

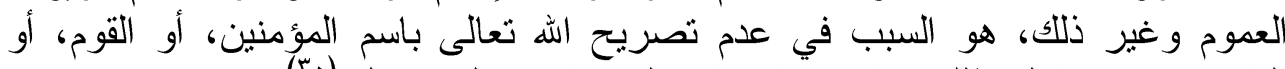

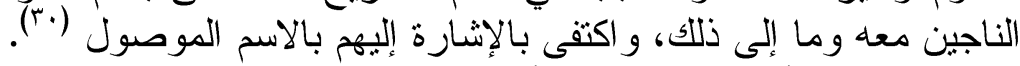

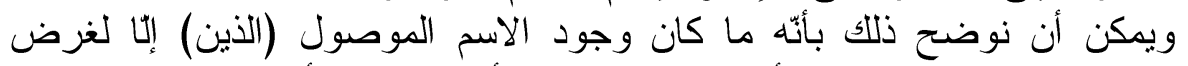

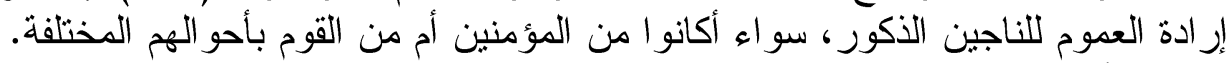

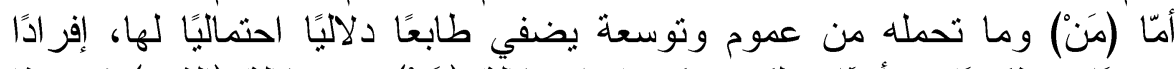

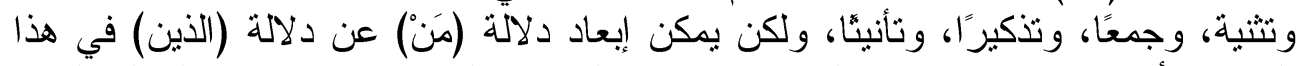

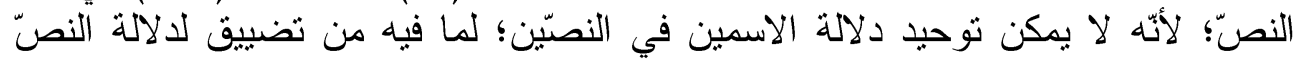

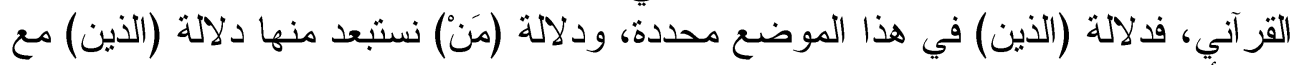

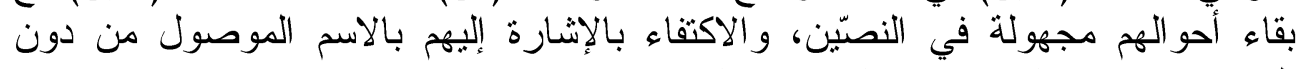
التصريح هو إعجاز يقتح به باب الاجنهاد.

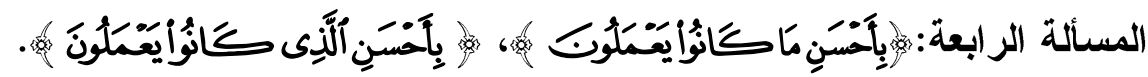

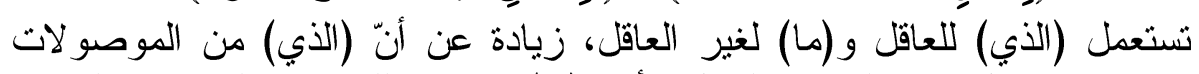

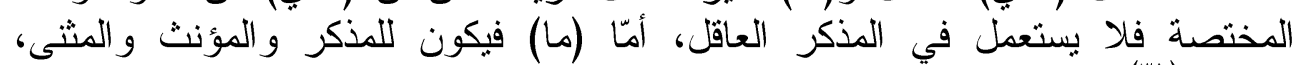

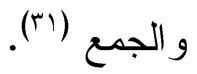




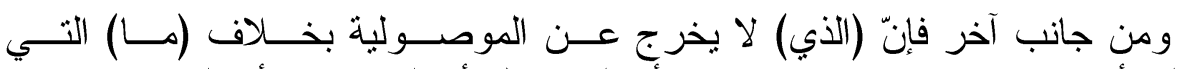

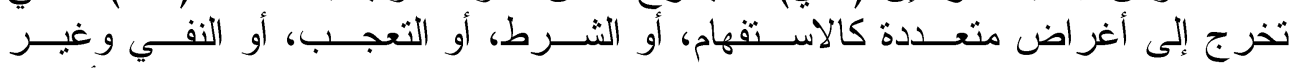

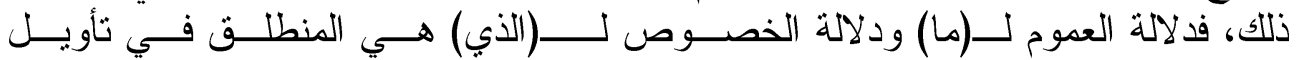

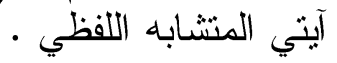

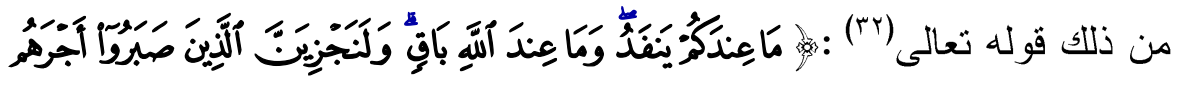

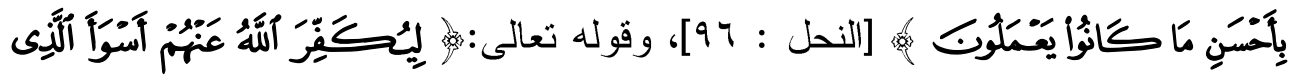

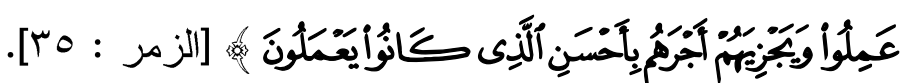

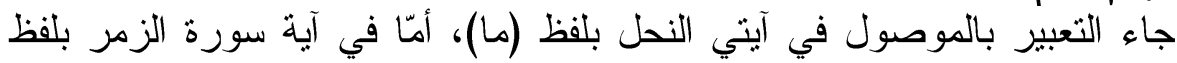

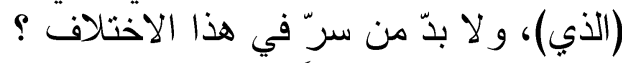

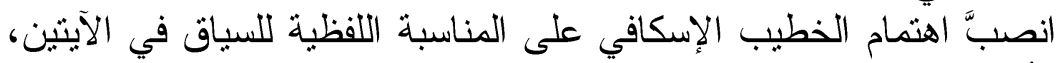

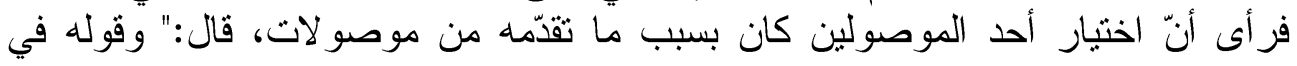

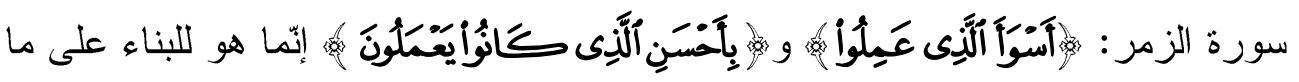

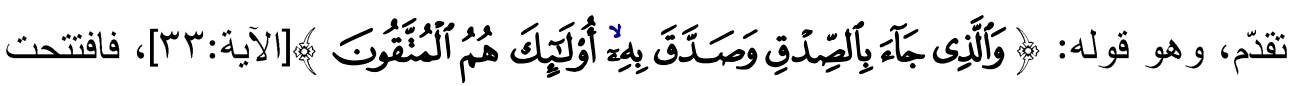

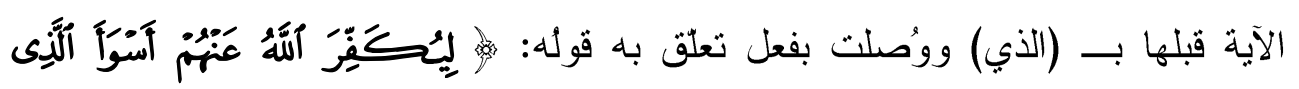

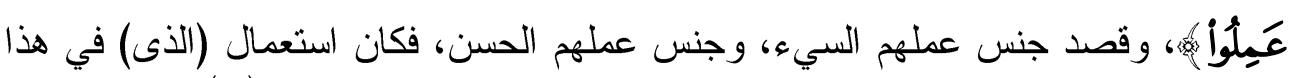

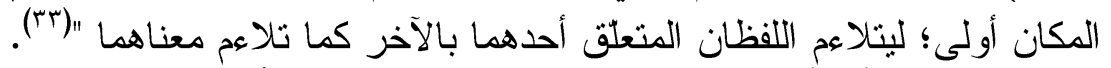

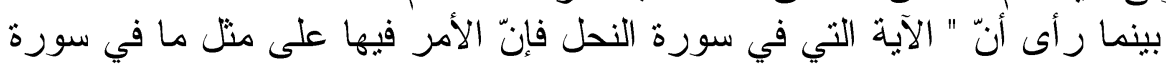

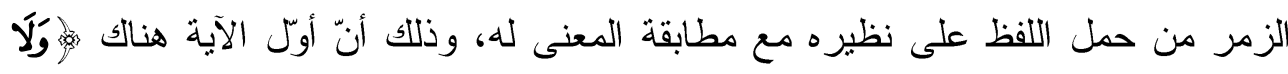

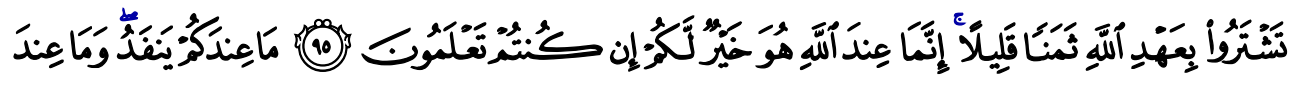

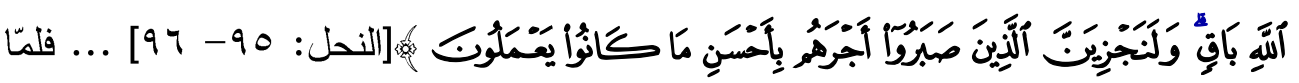

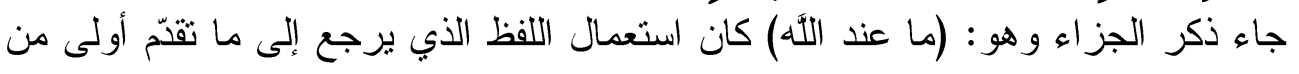

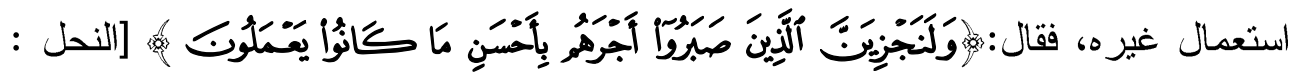

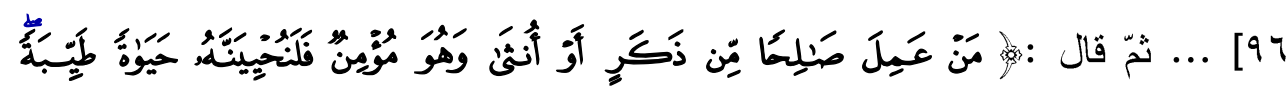

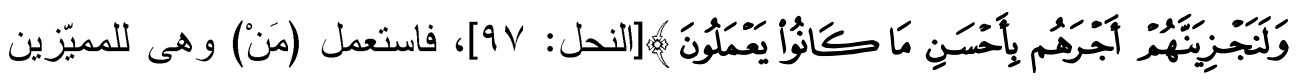

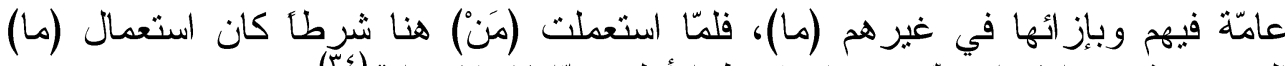

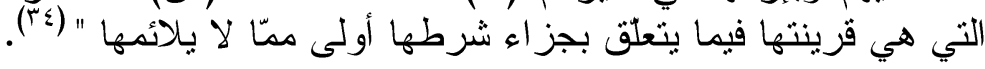

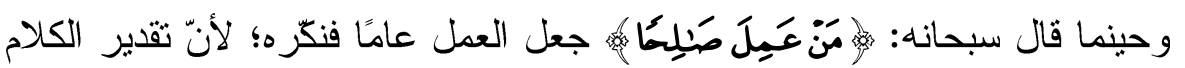

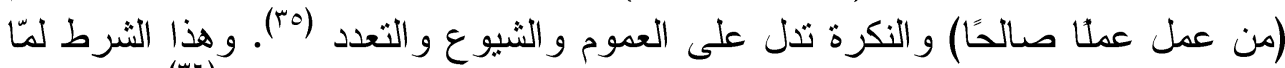

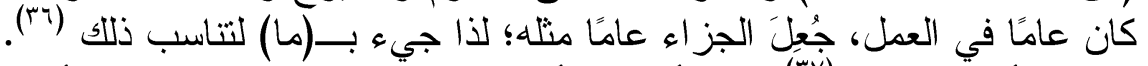

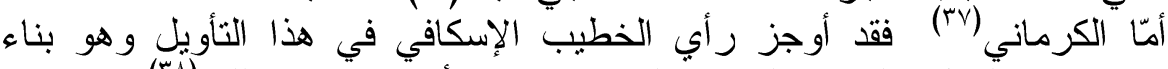

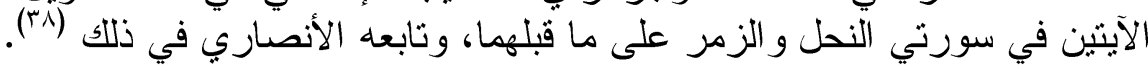


أمّا الغرناطي فأيّد الخطيب الإسكافي فيما جاء به من تأويل التناسب اللفظي، أمّا

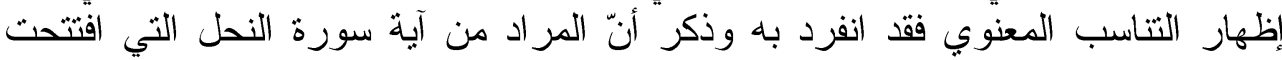

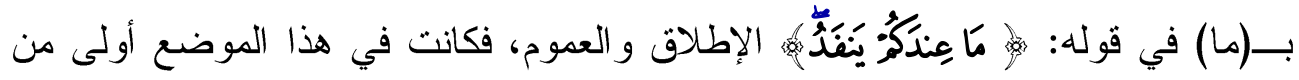
(الذي) فالإطلاق أملك بها وهو المقصود هنا، وتكررت في قوله تعالى: زولَّ وَمَا عِندَ آلَّهِ

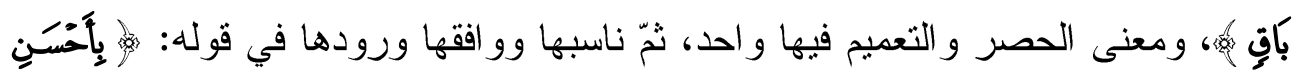

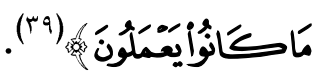

أمّا آية سورة الزمر وردت بمعنى الخصوص المقصود به طائفة بعينها، إذ سبقها

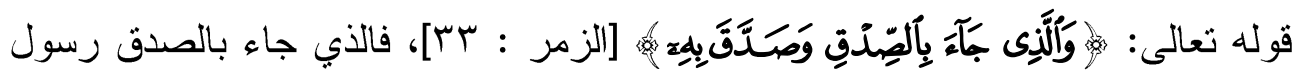
الله (علموسلهم) و الذي صدّق به منقدمو ا أصحابه، وهؤلاء لا يشاركهم في حالهم غيرهم،

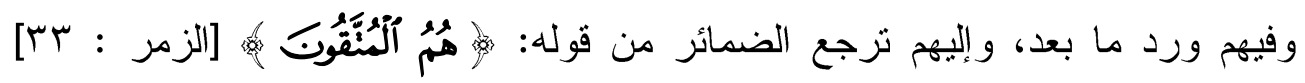

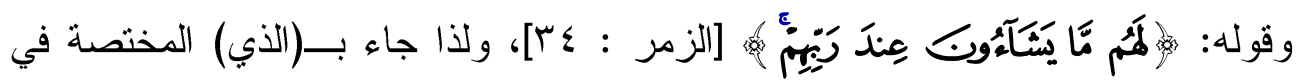

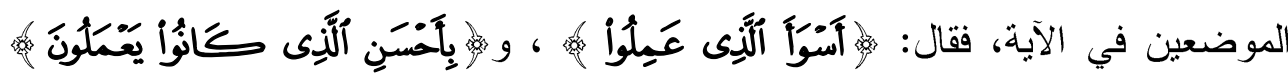

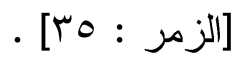

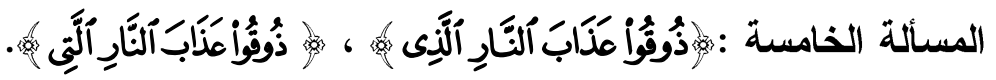

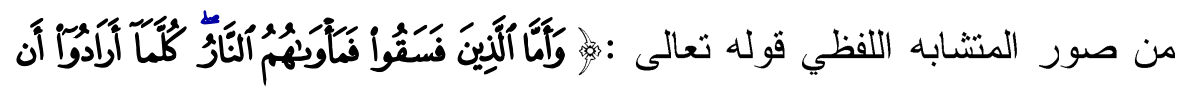

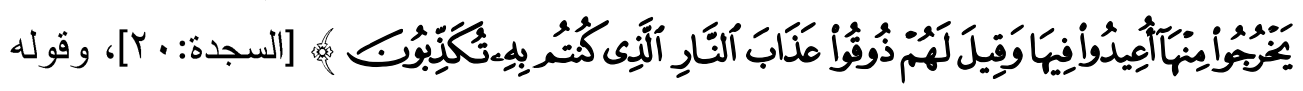

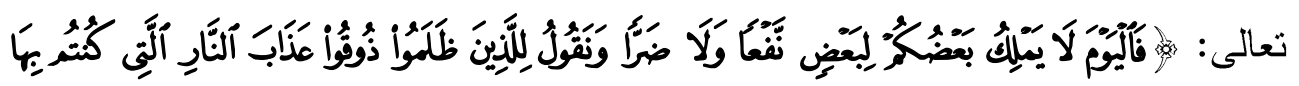

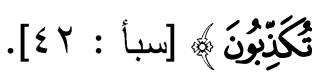

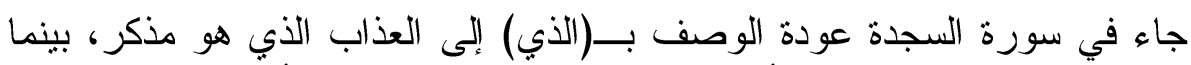

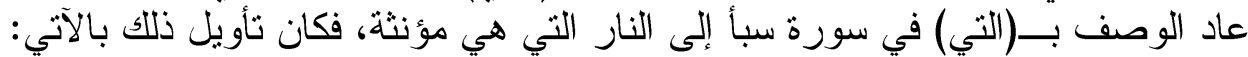

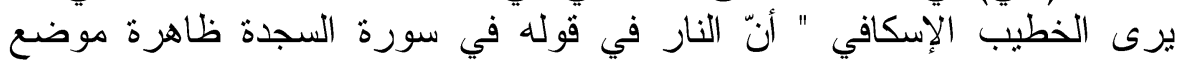

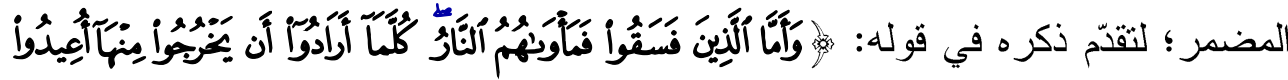
فيهبهام، فأضمرت في قوله: (أعيدو ا فيها) و أظهرت في قوله: (وقيل لهم ذوقو ا عذاب النار)

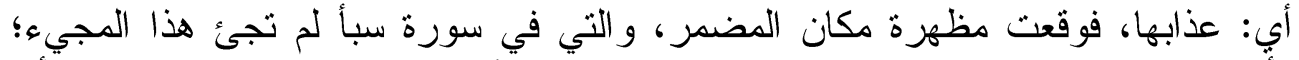

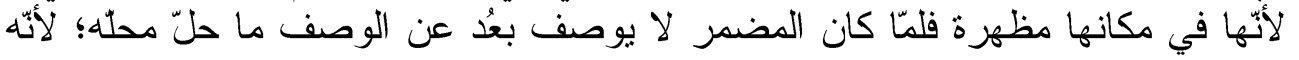

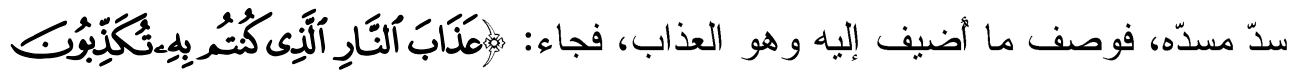
هُم، ولمّا لم يتقدّم ما في سورة سبأ ما منزلته منزلة المضمر صحّ الوصف له فأجري عليه 


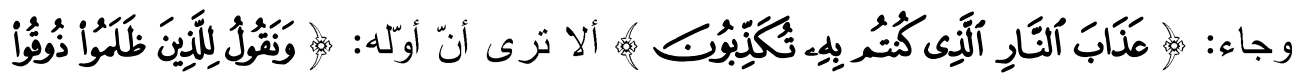

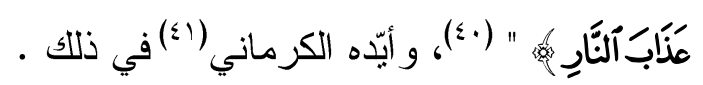

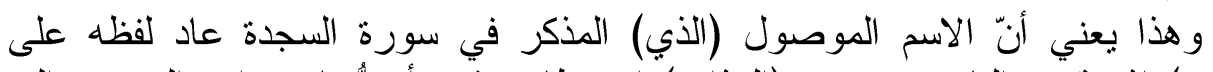

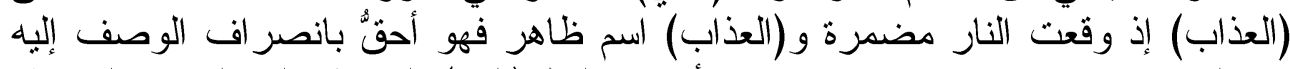

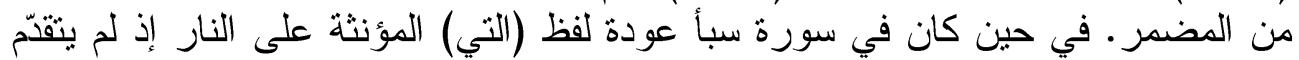

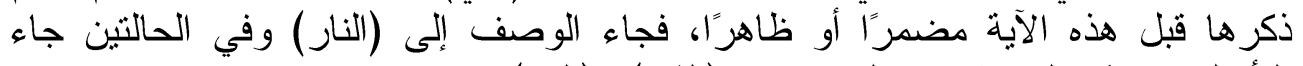

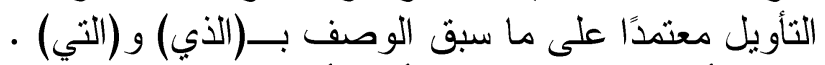

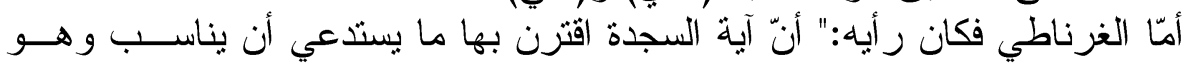

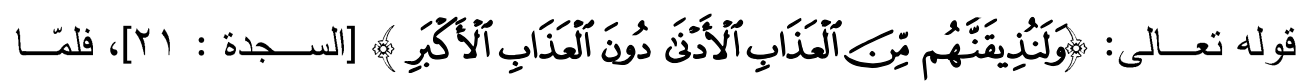

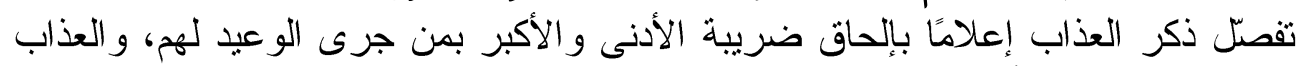

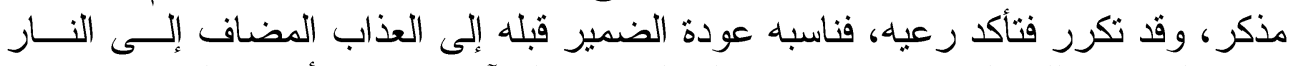

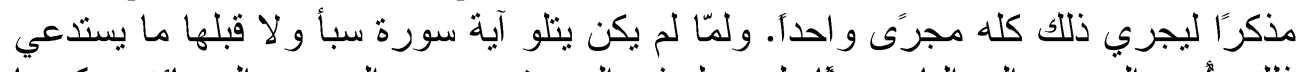

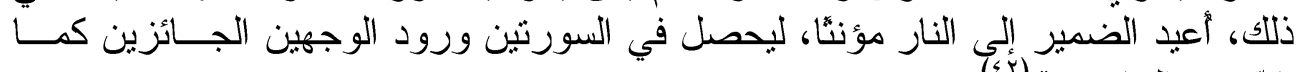

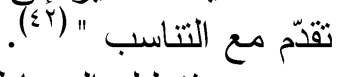

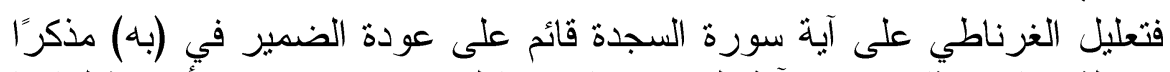

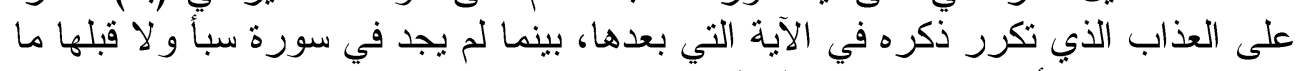

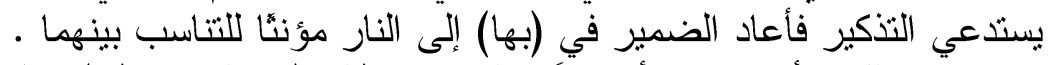

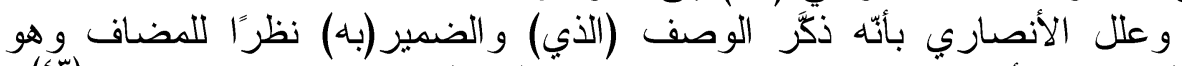

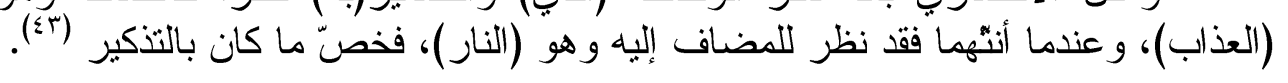

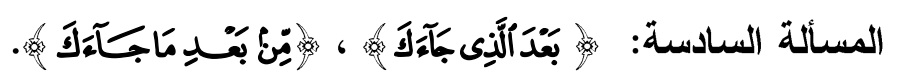

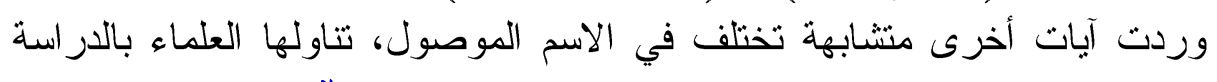

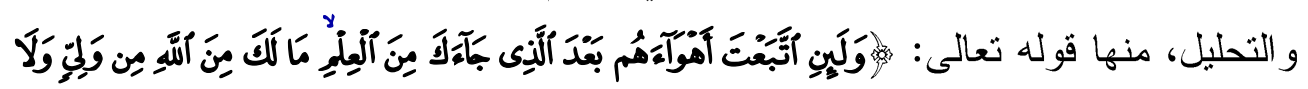

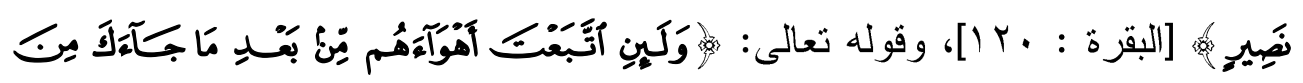

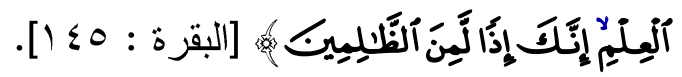

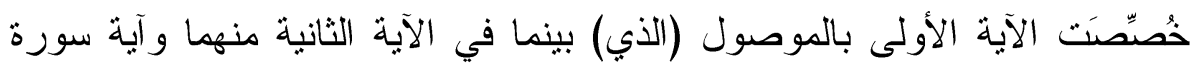

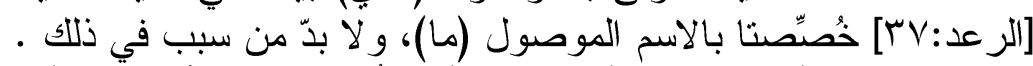

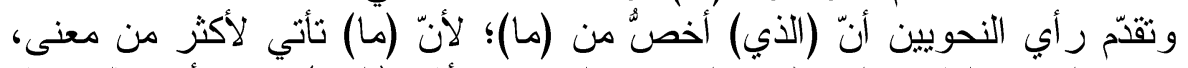

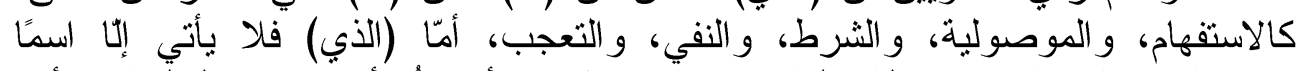

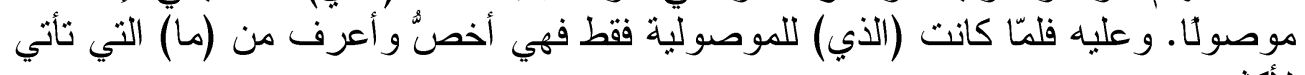

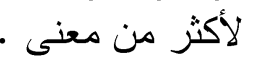
وقد وضّح الخطيب الإسكافي وجوه البيان في (الذي) بالآتي :

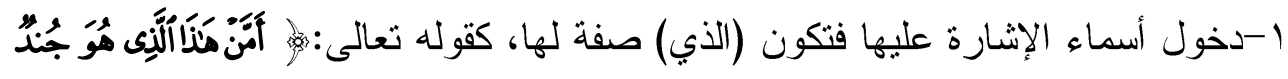

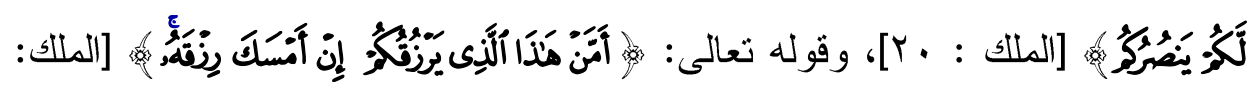




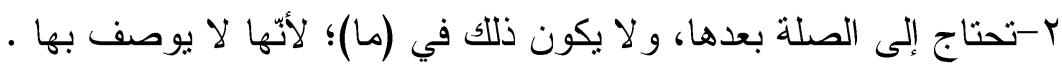

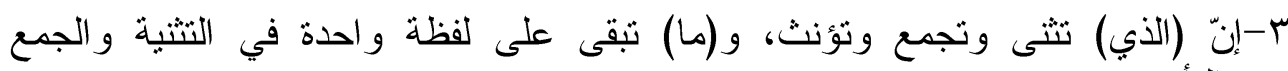

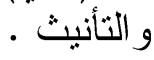

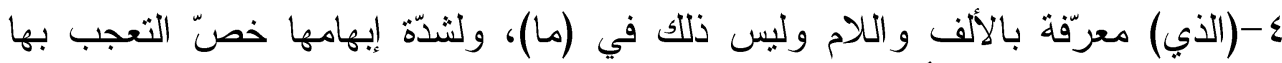

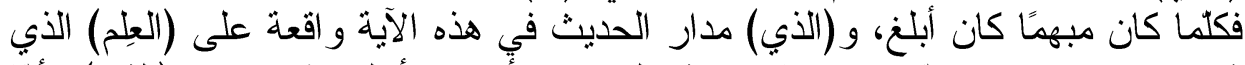

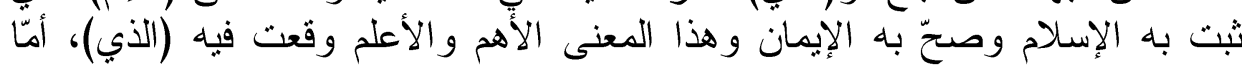

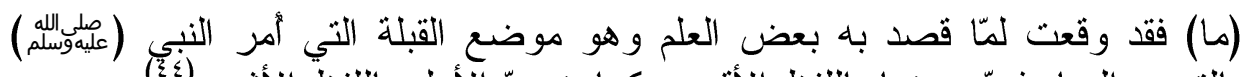

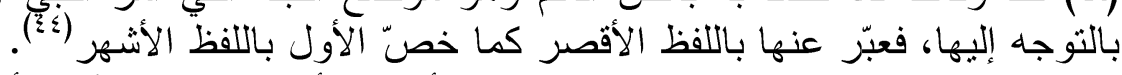

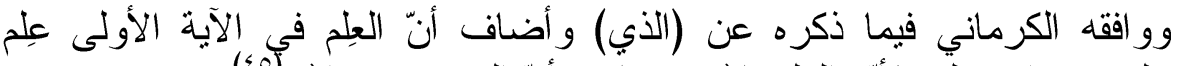

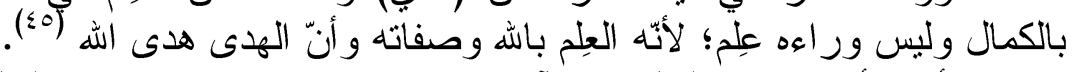

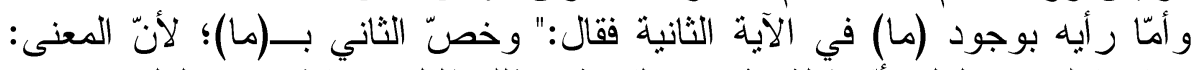

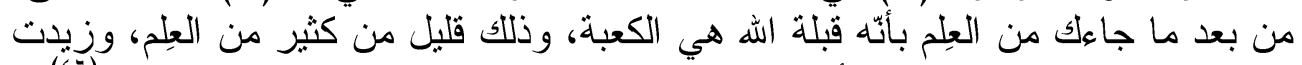

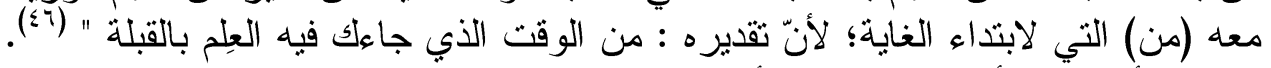

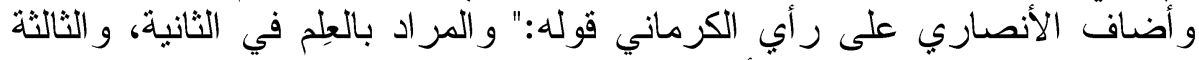

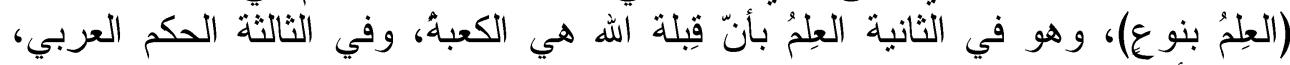

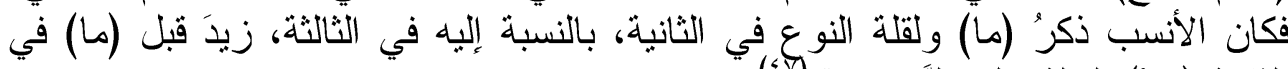

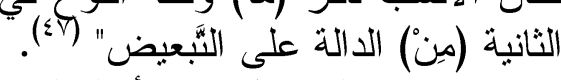

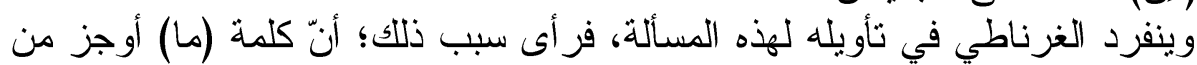

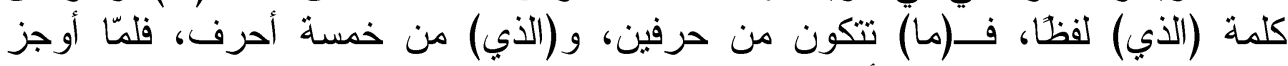

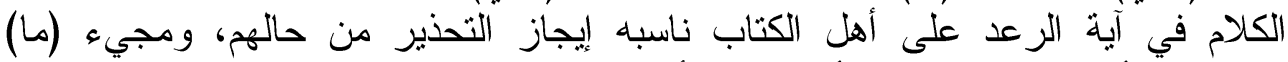

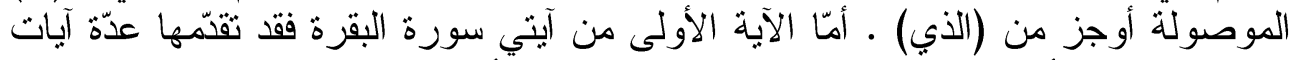

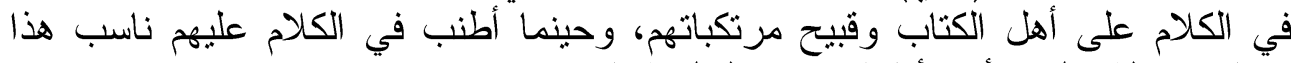

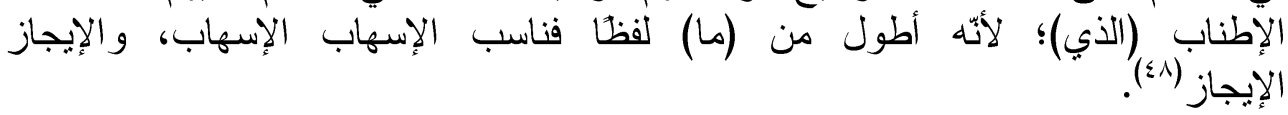

ور أى أنّ الآية الثانية [البقرة : 0 ؛ 1] جاءت " بعد إطناب زائد وتعريف بأكثر ممّا

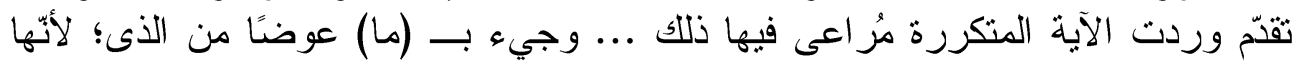

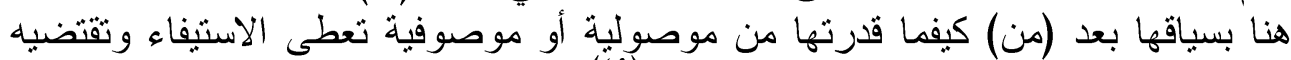

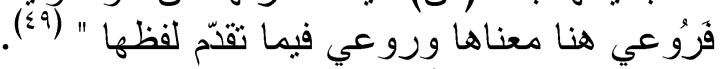

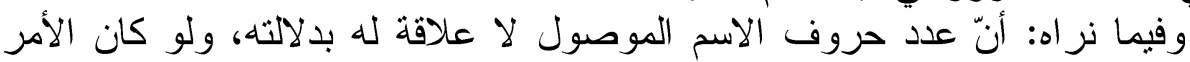

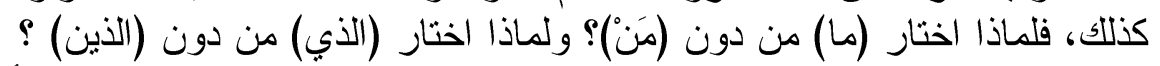

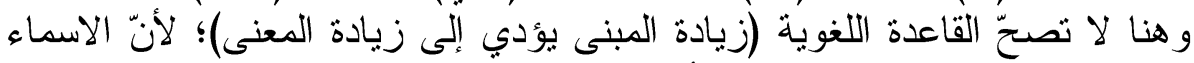

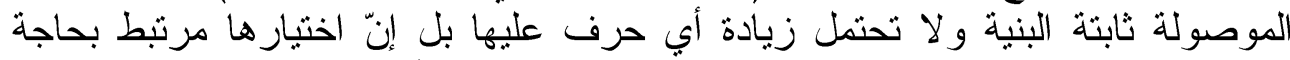
السياق إلى دلالتها، وليس لعدد الحروف علاّفة بالدلالة. و الها أعلم . 


\section{خاتمة البحث}

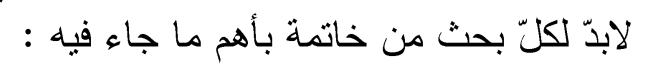

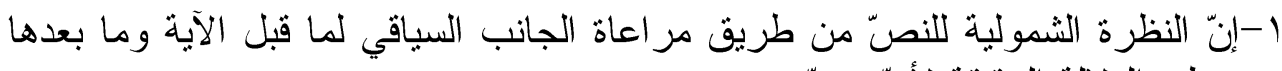

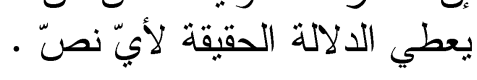

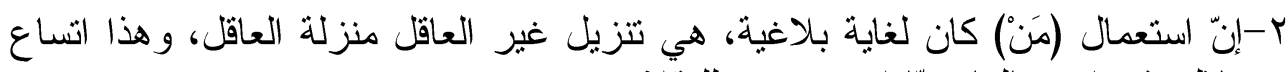

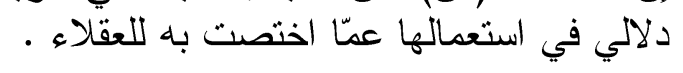

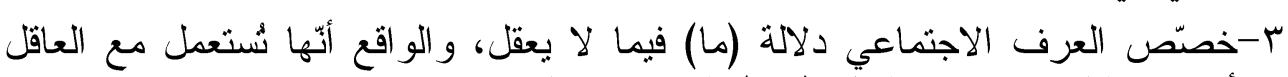

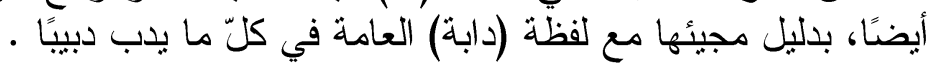

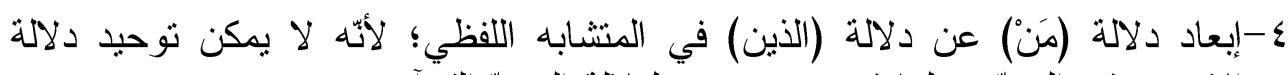

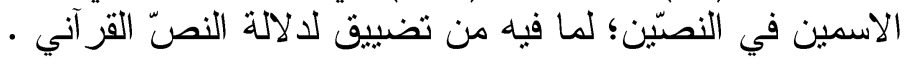

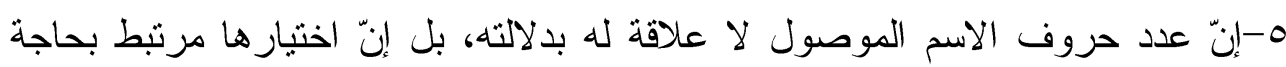

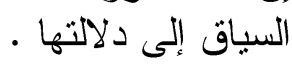




\section{Abstract}

INterpretation Of The Nominal Connectors In The Similar Verbal in

\section{HOLY Quran}

\section{By MUNA HAMID TAHA AL-NIAIMI}

\section{And Emad Mohammed Mahmoud Al-Bakhitawi}

Nominal connecters are regarded of knowledge that got its share from interpretation in books of the similar verbal in holy Quran because it affected significantly in Quran text .Sometimes we find a name connected to any particular verse, then comes with another nominal connector or identical verses, and both leave significant fingerprint we cannot find it without this variable. These nominal connectors arouse interest of the scholars of similar verbal in which stimulate them for more research and studies in order to reach its potential indications in Holy Quran as to confirm verbal miracle for this text. through following concerned issues that discover the nominal connecters indications secrets.

$$
\text { الامهو (مش }
$$

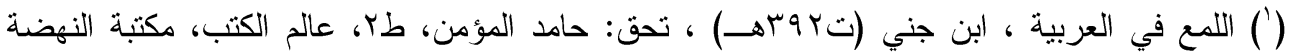

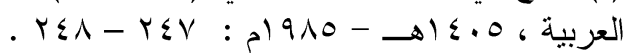

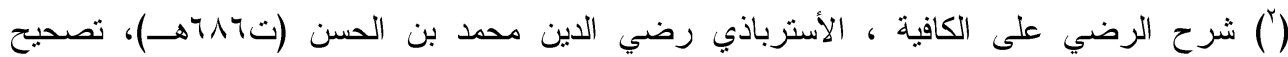

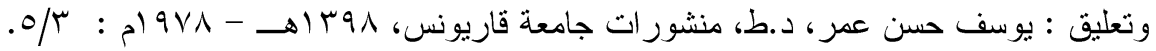

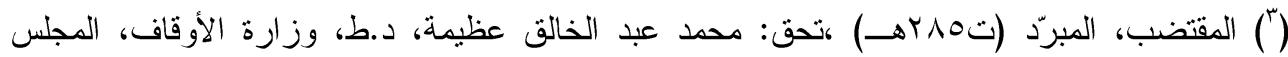

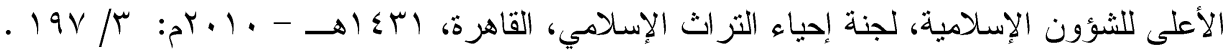

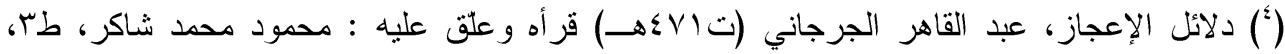

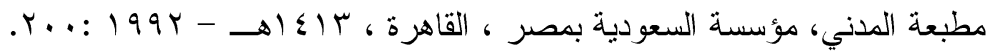

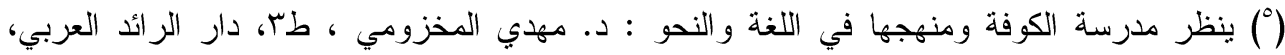

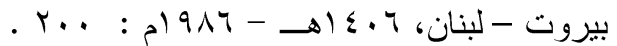

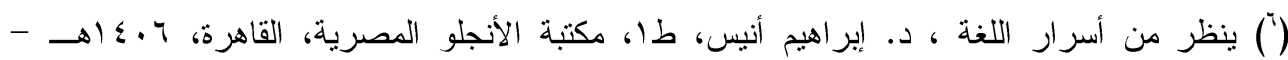
- rqr : a 1914

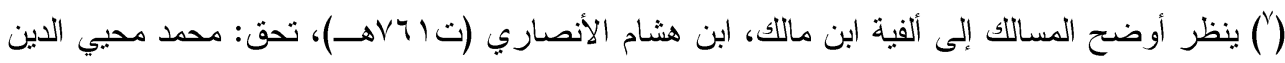

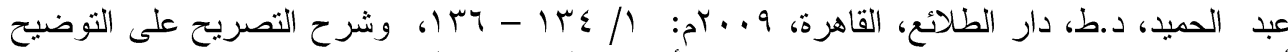

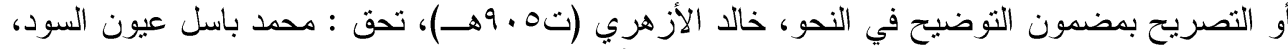

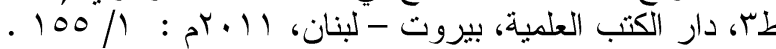

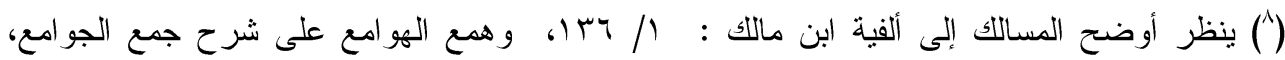

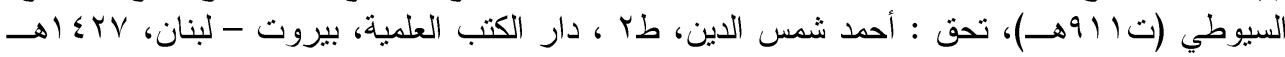

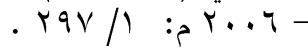

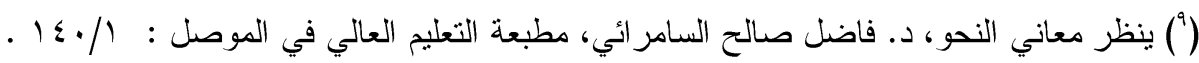




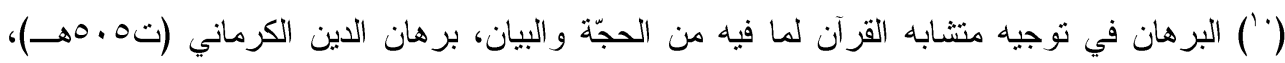

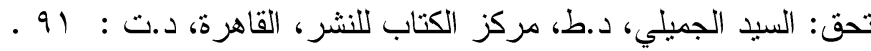

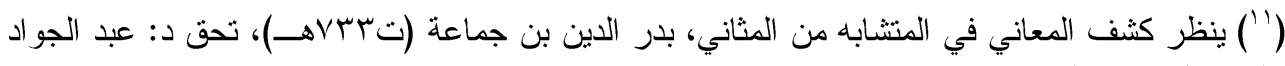

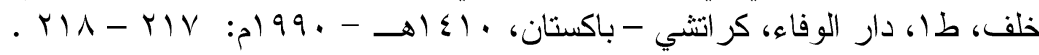

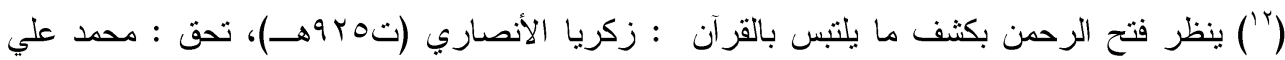

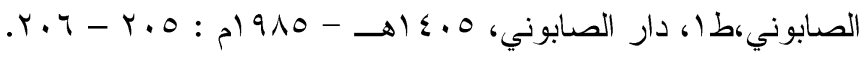

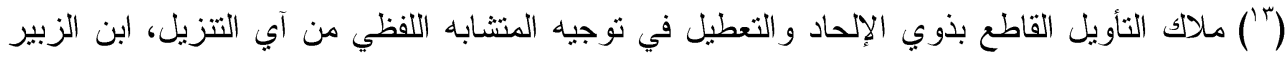

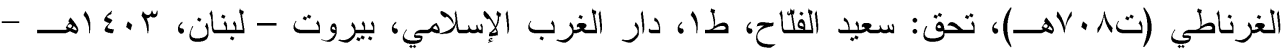
. V..

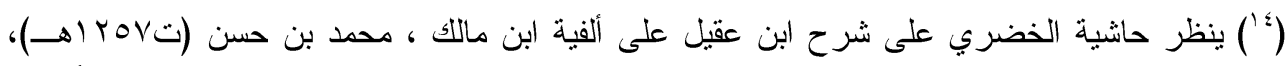

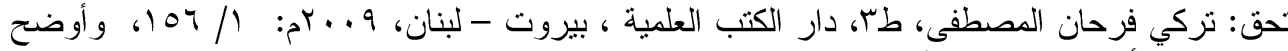

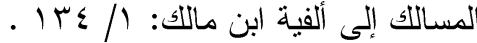

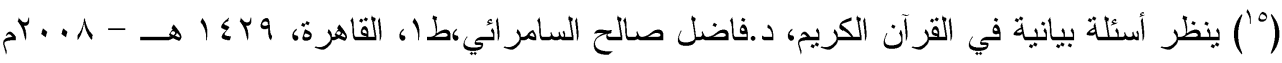

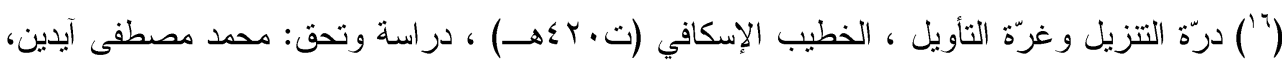

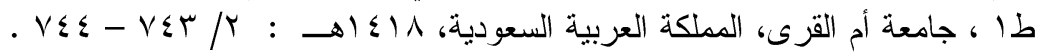
. V V

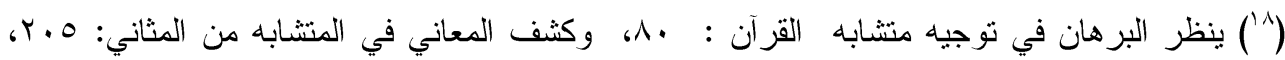

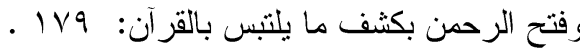

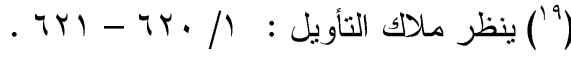

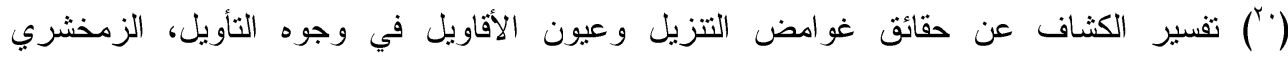

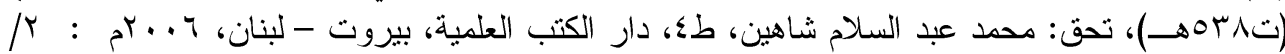
. $r \leq \varepsilon$

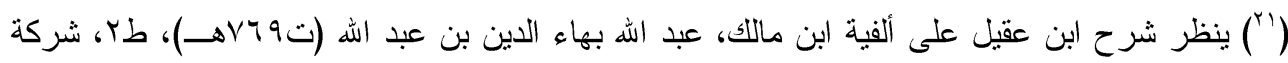

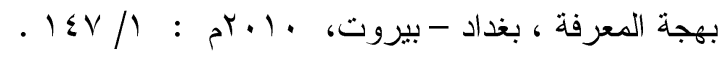

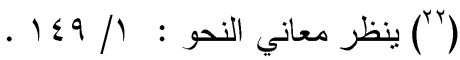

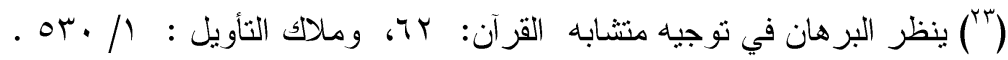

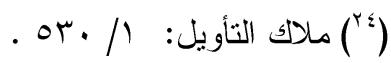

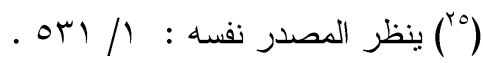

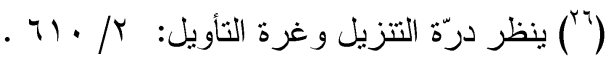

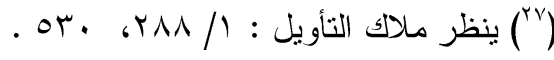

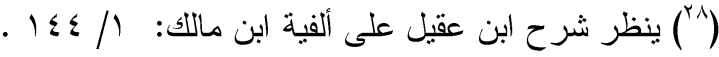

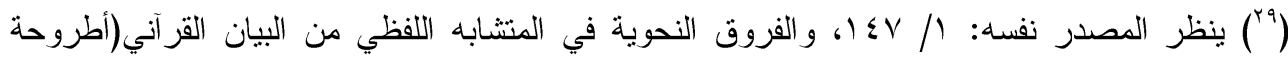

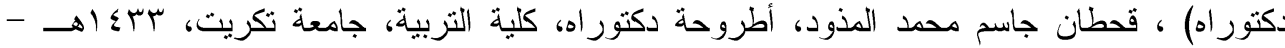
. $\leqslant Y$ :

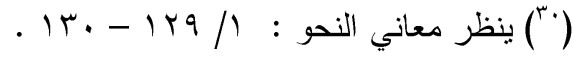

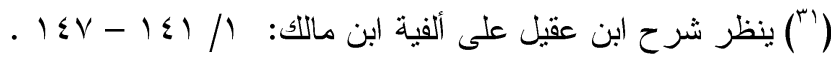




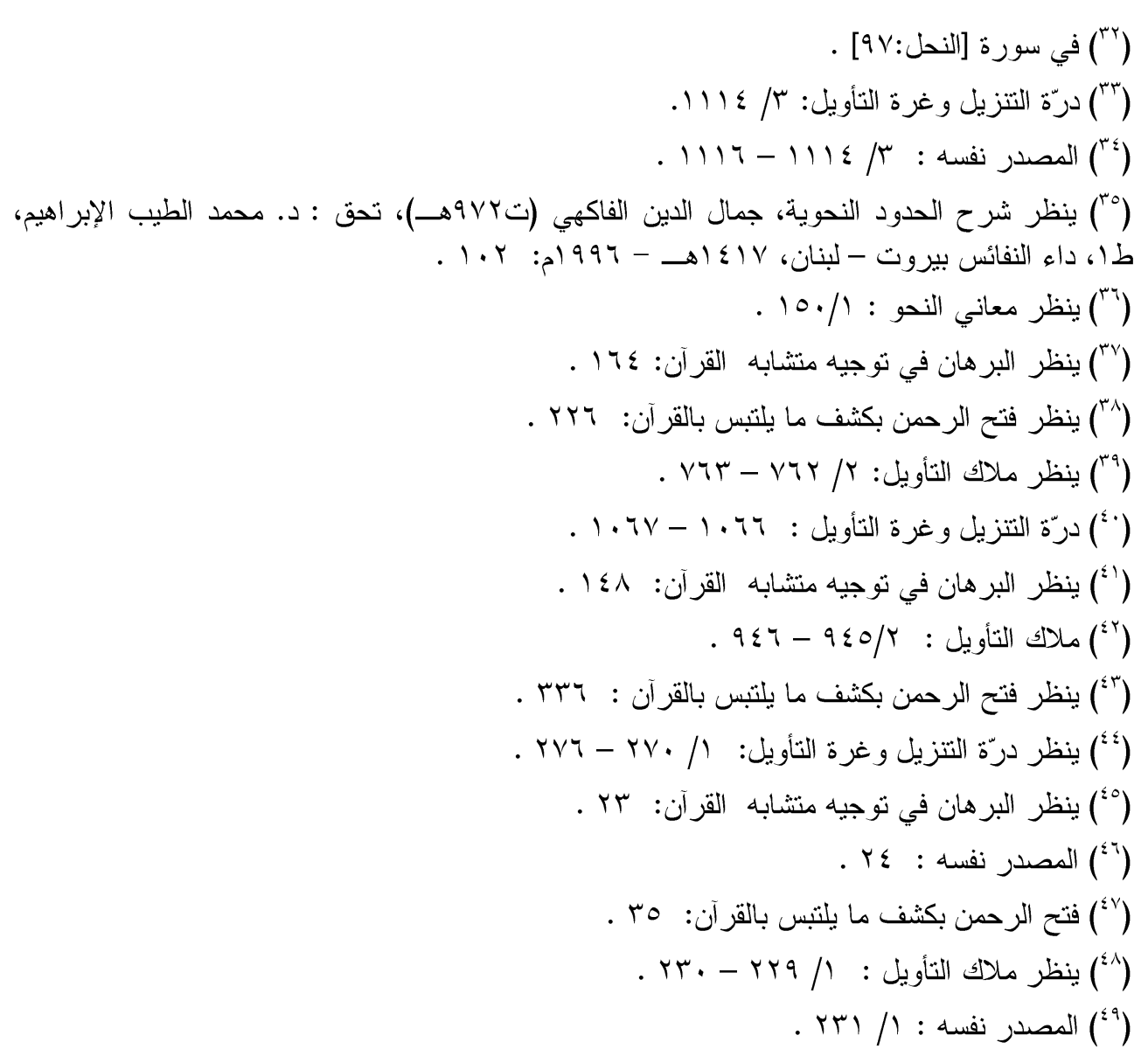

